\title{
EDITORIAL HISTORIA DE LA INFANCIA, EL PASADO DEL FUTURO
}

\author{
El niño enlaza el pasado con el futuro \\ Oswald Spengler (1880-1936)
}

El ser humano es un animal social gracias, en una parte fundamental, a la existencia de una infancia, producto lógico de nuestra evolución como especie. Un cráneo tan grande como el nuestro, en seres bípedos, solo era posible si el desarrollo cerebral se realizaba después de nacer. Lo que en un principio parece una terrible desventaja para la supervivencia, el nacer como criaturas sumamente indefensas, supuso en realidad un gran éxito adaptativo, pues está directamente relacionado con la creación de comunidades, necesarias para proteger a los más indefensos. Pero aunque la infancia ha acompañado a los seres humanos desde sus orígenes, la concepción de esta misma ha sufrido grandes variaciones a lo largo del tiempo y del espacio siendo, además de algo biológico, una construcción sociocultural.

Siempre ha existido una forma de dividir las etapas que recorren los seres humanos desde el nacimiento hasta la muerte; sin embargo la concepción de estos periodos es producto de las ideologías de cada época. Pese a la gran importancia de esas etapas y de la visión que de ellas se tiene en las diferentes sociedades, los historiadores no se preocuparon hasta hace relativamente poco tiempo de las cuestiones relativas a los niños, como sujetos activos y no meros miembros pasivos de la sociedad ${ }^{1}$. Al igual que sucede con la historia de las mujeres y de las relaciones de género, a la que dedicamos el monográfico $a_{\text {anterior }}^{2}$, la historia de la infancia requiere nuevos enfoques, nuevas fuentes, así como una reinterpretación de las ya conocidas. Asimismo se deben considerar diversas disciplinas para realizar un análisis desde diversas perspectivas. En el caso de la infancia resulta

1 Sirva 1960, año de la aparición de la pionera obra de Philippe Ariès, El niño y la vida familiar en el Antiguo Régimen (Madrid, Taurus, 1987, v. o. 1960), como inicio de esta preocupación en la historiografía.

2 «Historia y género: nuevas perspectivas», El Futuro del Pasado, 3, 2012. 
fundamental establecer vínculos entre la historia social y la historia de la educación, con la finalidad de comprender cómo se transforman las actitudes de los adultos hacia la infancia, y se construye la identidad (y la alteridad) infantil.

También del mismo modo que ocurre con las mujeres, los niños, «invisibles» hasta hace poco, se han convertido en protagonistas activos de la historia. La infancia es una categoría social más, que se relaciona con otras, como pueden ser el género o la clase social, y que al igual que estas ha variado enormemente a lo largo del tiempo y del espacio.

Por su condición particularmente vulnerable los niños han requerido medidas especiales de cuidado y protección y han sufrido todo tipo de abusos y maltratos. Al tratarse de individuos en proceso de socialización, la imagen que de ellos se ha tenido ha sido compleja, más cerca quizás de la naturaleza y de los instintos y por lo tanto potencialmente peligrosos, lo que hace necesaria la creación de diferentes herramientas de control y domesticación. Considerados en ocasiones como no-personas, los nińos han sido víctimas de las más diversas penurias y de la explotación por parte de los adultos.

Como vemos, existe un paralelismo entre muchos de los aspectos relacionados con la historia de la infancia y los que tienen que ver con la historia de las mujeres. Por supuesto en las diferentes formas de dominación ejercida hacia ambos colectivos, pero también en los logros (enormes, aunque no suficientes) conseguidos en los últimos tiempos.

La situación de la infancia se ha ido transformando de manera muy notable desde las revoluciones ilustradas del siglo XVIII y principios del XIX, cuando los niños adquirieron el rango de ciudadanos con derechos, deberes y libertades, y aparecieron progresivamente los sistemas nacionales de enseñanza y sociedades filantrópicas destinadas a la protección de la infancia. Sin embargo, paralelamente a esta nueva consideración de la infancia, seguía existiendo una realidad material que en ocasiones era aún más dura que en generaciones anteriores, con gran cantidad de niños que vivían en situaciones lamentables y eran explotados productivamente en fábricas y minas.

A comienzos del siglo XX, en 1924, la respaldó la , el primer manifiesto sistemático sobre los Derechos del Niño, conviniendo la necesidad de poner a disposición del niño todos los medios necesarios para su correcto desarrollo, asegurando su protección física y mental y protegiéndolo ante la explotación y la falta de sustento. Se planteaba también que, en caso de desastre (como el que por desgracia llegaría poco después, con la II Guerra Mundial), la infancia sería la primera en recibir auxilio. Los cinco puntos en los que se concretó la Declaración se centraban más en las obligaciones de los adultos que en los derechos de los nińos, porque su cumplimiento seguía dependiendo de la voluntad de los primeros. 
Posteriormente, la misma Asamblea General creó el (UNICEF) (1950), y aprobó la (1959), donde se mantuvo el espíritu y la idiosincrasia de la de 1948, que fue revisada veinte ańos después, coincidiendo con el (1979). Las iniciativas precedentes serían ratificadas en 1989, cuando la adoptara una nueva ${ }^{3}$. Desde entonces es innegable que se ha avanzado mucho en la compresión de las necesidades de la infancia, pero también que los logros no han sido completos ni universales.

A finales de los años 80 y principios de los 90 muchos países pobres realizaron ajustes reduciendo el gasto público en servicios básicos y ayudas. Estos recortes fueron sufridos por los más necesitados, especialmente los niños. Los estados no se han interesado lo suficiente por resolver las tremendas desigualdades existentes y la política de créditos al desarrollo (con grandes intereses) del Banco Mundial no ha ayudado en absoluto a que los países en vía de desarrollo, fundamentalmente en África, Asia e Iberoamérica, salgan de la miseria. Tras la caída del muro de Berlín la ayuda oficial de desarrollo se redujo considerablemente, al dejar de servir como una herramienta más en la lucha de bloques.

Por desgracia, un gran número de países no alcanzará los (ODM) de la ONU4 firmados en 2000 y planteados para 2015. Los niños de los territorios más desfavorecidos sufrirán las consecuencias de este fracaso.

Pero ni siquiera en los países más desarrollados la situación es óptima, y parece muy lejano el cumplimiento del principio de la CDN referente a la participación infantil como parte más de la ciudadanía. Los estados no han cumplido el compromiso de garantizar a los nińos el derecho a participar y expresarse libremente en los asuntos que les afecten, es decir, de poder actuar en la esfera pública y no solo en el ámbito privado.

Actualmente, la tremenda crisis económica somete a una dura prueba a los poderes políticos y a la sociedad en su conjunto sobre los compromisos con la infancia, prueba en la que desafortunadamente estamos saliendo muy mal parados. Mientras el índice de pobreza crece a toda velocidad, afectando más a los nińos que a cualquier otro grupo de edad, las ayudas y los servicios públicos se reducen y la inequidad en la infancia aumenta drásticamente. La falta de compromiso por una educación de calidad, justa y equitativa tiene como consecuencia un aumento de las desigualdades sociales.

Sobre algunos de los aspectos aquí tratados tuvimos ocasión de reflexionar en el volumen publicado con motivo del veinte aniversario de la CDN: HERNÁNDEZ HUERTA, José Luis; SÂNCHEZ BLANCO, Laura; PÉREZ MIRANDA, Iván (coords.), Temas y perspectivas de la educación. La infancia ayer y hoy, Globalia Ediciones Anthema, Salamanca, 2009.

4 La Declaración recoge ocho Objetivos referentes a la erradicación de la pobreza, la educación primaria universal, la igualdad entre los géneros, la mortalidad infantil, materna, el avance del VIH/ sida y el sustento del medio ambiente. 
Los derechos de la infancia están siendo pisoteados, pues no resulta «rentable» mantenerlos, y el cumplimiento de la CDN queda como una utopía más que no podemos permitirnos económicamente.

Los niños son tratados no tanto como una realidad presente, salvo por la "carga» que representan, sino como un mero proyecto de futuro, lo que se muestra ideológicamente en planes de estudio pensados más para crear individuos productivos, dóciles y adoctrinados que en fomentar el propio espíritu crítico que deben tener los ciudadanos dentro de una sociedad democrática. Parece importar más su futura incorporación al mercado de trabajo (como si fuesen una mercancía más), que su formación integral como seres libres y responsables.

Las ciencias sociales y las humanidades constituyen poderosas herramientas para la construcción de un mundo más justo y solidario, para que las utopías se constituyan en realidades. Y desde luego el conocimiento del pasado es fundamental para poder comprender el presente y actuar en él. El incluido en este número pretende ser una contribución más al conocimiento y difusión de la historia de la infancia y sus representaciones.

Como en números anteriores, la sección recoge artículos de una gran diversidad temática y cronológica, todos ellos de gran interés.

En la sección, Manuel Villegas reconstruye, a través de una Licencia del Ejército, la historia personal de un sargento, Eduardo Ruiz Alguacil, que participó en la guerra de Filipinas. El autor trata de mostrar, a través de este caso, cómo «la Historia no sólo se gesta en los grandes hechos llevados a cabo por las multitudes o por las intervenciones de los gobernantes de las naciones, sino también por las acciones individuales realizadas por el ser humano, único y verdadero motor de la Historia».

En, donde recogemos nuevas e interesantes publicaciones sobre temas de historia, en esta ocasión presentamos, de la mano de Cecilia Nocilli, su directora científica, la revista "ActaLauris. Orationes y lectiones de la Academia del Lauro», vinculada al cenáculo humanista amparado bajo el mecenazgo de Il Gentil Lauro, que pretende ser un espacio de excelencia científica abierto al debate sobre la cultura del Renacimiento y a la que auguramos un brillante futuro.

En la sección se da noticia en esta ocasión de seis novedosas obras, de temática muy diversa.

Para cerrar el número se ha incluido un emotivo de la escritora Olga Zamboni, relacionado con el tema del monográfico y que trata sobre el descubrimiento de la muerte por parte de dos nińas. 
El presente número sigue la línea de los anteriores, pero presenta también novedades importantes que creemos muestran cómo el proyecto va consolidándose. Nos gustaría destacar la nueva apariencia de la revista, más atractiva y elegante, gracias al buen hacer de Javier González-Tablas. Asimismo, la incorporación de la plataforma OJS en la página web supone un paso importante para la modernización, la difusión y accesibilidad de la revista, que también favorece la incorporación a nuevas bases de datos y repositorios internacionales diversos como EBSCO o DRJI.

Pese a las muchas dificultades, fruto de la difícil situación actual, seguimos creyendo en nuestro trabajo y confiamos en que los esfuerzos realizados por quienes, de diversas formas, colaboran en merezcan la pena. A todos ellos, miembros del equipo editorial, autores, informantes y lectores, nuestro agradecimiento.

Dr. Iván Pérez Miranda

Director
Dra. Laura Sánchez Blanco

Coordinadora del Monográfico

Salamanca, mayo de 2013 